\title{
Konstruksi Budaya pada Tubuh Perempuan Bali dalam Novel Kenanga Karya Oka Rusmini
}

\author{
Wista Ayu Pratiwi*, Baiq Annisa Yulfana, Muh. Fathan Zamani \\ Magister Sastra, Fakultas Ilmu Budaya, Universitas Gadjah Mada \\ *Penulis Koresponden: wistaayupratiwi95@gmail.com
}

\section{ABSTRAK}

Penelitian ini bertujuan untuk mengeksplorasi posisi perempuan kasta Brahmana di Bali yang di konstruksi oleh budaya Bali sebagai perempuan yang harus mematuhi aturan-aturan yang sudah digariskan. Kenanga menanggung kebusukan masa lalu, ketidakberdayaannya melawan dirinya yang berada dalam bayang-bayang sebuah peristiwa kelam yang dilakukan oleh lelaki. Laki-laki tersebut kini menjadi adik iparnya, yang mengawini adiknya yaitu Kencana. Terjadi pergolakan batin untuk melawan, tetapi tubuh menjadi saksi bisu ketidaksetaraan dalam kehidupan Kenanga. Penelitian ini akan menggunakan teori Judith Butler mengenai bagaimana 'sex' atau jenis kelamin sebagai fakta biologis dan 'gender' merupakan interpretasi kebudayaan. Dalam hal ini Kenanga sebagai gadis Bali terperangkap dalam kebudayaan, kenyataan bahwa adiknya Kencana menikah dengan lelaki yang Kenanga cintai dan telah menanamkan benih pada dirinya.

Kata Kunci: konstruksi budaya; kesetaraan; pergolakan batin

\section{ABSTRACT}

This study aims to explore the position of Brahmin caste women in Bali which are constructed by Balinese culture as women who must obey the rules that have been outlined. Remembering to endure the rottenness of the past, her helplessness against her being in the shadow of a dark incident committed by a man. This man is now his brother-inlaw, who married his younger brother, Kencana. There is an inner struggle to fight back, but the body is a silent witness to the inequality in the life of the Kenanga. This study will use Judith Butler's theory of how "sex" or gender is a biological fact and "gender" is a cultural interpretation. In this case, Kenanga as a Balinese girl is trapped in culture, the fact that her sister Kencana is married to a man who Kenanga loves and has planted seeds in her.

Keywords: cultural construction; equality; inner turmoil

\section{PENDAHULUAN}

"Dan terjadilah peristiwa itu. Entah bagaimana ceritanya, tiba-tiba Bhuana sudah berada dalam kamar Kenanga. Perempuan itu meringkuk di ranjang tanpa busana. Tubuhnya yang telanjang sedikit berkilau tersiram temaram cahaya pagi." (Rusmini, 44: 2017)

Kutipan di atas menceritakan seorang perempuan Bali bernama Kenanga yang tubuhnya diperlakukan seolah-olah milik Bhuana. Hal tersebut merupakan sebuah kesalahan besar bagi Kenanga dan Bhuana, percintaan mereka dilakukan tanpa ikatan perkawinan. Kenanga menanggung malu dan aib seumur hidupnya yang diberikan oleh Bhuana. Tidak ada yang mengetahui bahwa kehadiran gadis kecil bernama Intan dalam keluarga Kenanga, adalah hasil persetubuhan Kenanga dan Bhuana.

Terlihat bagaimana sebuah monumen bernama kebudayaan mampu mengkonstruksi identitas perempuan sebagai pihak yang terkungkung dalam bingkai kasta yang saat ini masih sangat melekat dalam adat istiadat pulau Dewata. Beberapa pihak mengklaim bahwa isu kesetaraan 
bukanlah masalah bagi masyarakat Bali yang kental dengan budaya. Klaim ini kemudian muncul mengingat masyarakat Bali memiliki stereotip bahwa perempuan adalah sosok pekerja keras, tidak pernah mengeluh, patuh, dan berbakti pada keluarga (Udasmoro, 2018: 18).

Seperti dalam wawancara yang dilakukan Iness Wynn (2016) terhadap Cok Sawitri, salah seorang pegiat sosial di Bali. Sawitri menyatakan bahwa mereka tidak memliki masalah dalam kaitannya dengan ketidaksetaraan gender di Bali, yang menjadi masalah bagaimana menjelaskan perspektif kebudayaan Bali terhadap feminisme dalam bahasa yang mudah dipahami kaum terpelajar.

Klaim beberapa orang seperti ini berbanding terbalik dengan kenyataan dimana terdapat ratusan penelitian tentang pergerakan feminisme dalam sosio-kultur masyarakat Bali. Seperti dalam buku Perempuan Bali Tempoe Doeleoe karya I Nyoman Darma Putra dikatakan bahwa perempuan Bali telah mengenal feminisme sejak setengah abad silam. "di saat pembuatan jalan belum menggunakan teknologi hotmix..." (Putra, 2003). Pertentangan terhadap sistem patriarki sekaligus sistem kasta menjadi pokok bahasan yang kemudian banyak diangkat.

Dalam hal ini, Oka Rusmini sebagai pengarang seringkali dinilai sebagai penyair perempuan "pemberontak" terhadap konstruksi gender. Ia seringkali menampakkan protes atas dominasi laki-laki dalam karya sastranya. Menurut Nuryana Asmaudi (2003), Oka Rusmini sering menyuarakan harkat perempuan diantara dominasi patriarkis, terutama dalam kehidupan dan budaya Bali. Sebagai orang Bali Oka Rusmini (berkasta Brahmana) sangat dekat dengan permasalahan-permasalahan perempuan Bali dan seksualitas perempuan akibat kasta yang menghegemoni. Hal itu pula yang berusaha ditunjukan Oka Rusmini melalui novel Kenanga.

Pada proses ini terjadi ketimpangan dalam kehidupan Kenanga sebagai perempuan. Dirinya menerima dan menyimpan luka itu tanpa ada yang mengetahui. Ia pun menyibukan dirinya dengan pekerjaannya untuk lari dari hal tersebut. Salah satu yang dapat disoroti dalam novel ini adalah penggambaran dua karakter perempuan yang berbeda yakni Kenanga dan Kencana. Kencana memiliki karakter perempuan yang berusaha patuh terhadap tradisi adat Bali dan Kenanga memiliki karakter perempuan yang memiliki banyak ambisi dan tidak mau terkekang dengan adat dan tradisi.

Tokoh Kencana dan Kenanga menjadi gambaran perempuan Bali yang berusaha patuh terhadap tradisi walau Kenanga merasa hidupnya diperlakukan tidak adil karena kenyataan. Kenanga digambarkan sebagai perempuan yang berambisi, penuh dengan impian dan baginya bahwa hidup adalah untuk berkarier sehingga, sifat tersebut diturunkannya pada Intan anaknya. Kenanga berusaha mendidik Intan menjadi perempuan yang berambisi dan tidak mau kalah dengan tradisi.

Pemosisian perempuan sebagai individu yang bekerja disektor domestik terus diproduksi. Hal ini tentu erat kaitannya dengan tujuan untuk memperkokoh posisi kelompok maskulin. Tradisi dan budaya kemudian dibuat sedemikian rupa sebagai sesuatu yang secara otomatis menjadi 
pengawas guna memastikan segala hal berjalan sesuai pola yang telah dibentuk. Budaya dan tradisi dihadirkan untuk membentuk perempuan dalam konsep yang feminin, dimana perempuan dibentuk menjadi sosok yang lemah-lembut, emosional, keibuan dan berbagai karakter yang membuat mereka terlihat lebih cocok berada diranah domestik dibanding ikut mengambil peran di ranah publik. Inilah yang dimaksud dengan budaya dan tradisi sebagai pengawas untuk terjaganya posisi kaum laki-laki sebagai subjek yang memegang kendali, terutama di ranah publik.

Berdasarkan penjelasan di atas bahwa perempuan Bali mengalami penundukan meskipun ia berasal dari kasta yang tertinggi, yaitu kasta Brahmana, maka pertanyaan yang disampaikan dalam artikel ini bagaimana budaya mengkonstrusikan tubuh perempuan Bali yang terdapat dalam novel Kenanga karya Oka Rusmini.

\section{TEORI DAN METODE PENELITIAN}

Kesetaraan gender merupakan persoalan yang masih hangat dibicarakan diberbagai ruang publik hingga saat ini. Berbagai media dimanfaatkan guna mengangkat isu-isu kesetaraan gender yang dianggap masih belum benar-benar menemukan titik terang. Konstruksi budaya yang sudah dilakukan sejak berabad-abad lamanya tentunya tidak dapat diubah dengan mudah. Dalam bukunya The Dialectic of Sex: The Case for Feminist Revolution, Shulamith Firestone (1970), berargumen bahwa awal dari ketidak setaraan gender adalah fungsi biologis perempuan secara fisik, psikologi dan sosial menempatkan perempuan sebagai yang melahirkan, menyusui dan membesarkan anak. Fungsi biologis yang bersifat dikotomis antara laki-laki dan perempuan ini kemudian menempatkan laki-laki dan perempuan dalam kutub dan ranah yang berbeda. Fungsi biologis inilah yang kemudian dibawa ke berbagai ranah baik sosial, kultural maupun politik yang kemudian memetakkan perempuan berada di ruang domestik sedangkan laki-laki berada di ruang publik.

Dalam feminis Judith Butler Beauvoir bahwa ada sebuah perbandingan dimana 'perempuan' merupakan ide historis dan bukannya fakta alami. Ada 'sex' atau jenis kelamin sebagai fakta biologis dan 'gender' yang merupakan interpretasi kebudayaan. Menjadi 'female' adalah fakta yang tak memiliki makna. Menjadi 'woman' memaksa tubuh untuk menjadi sesuai dengan ide sejarah mengenai 'woman' itu sendiri, menjadikanya tanda kebudayaan. (Butler, 1988: 522). Spivak dalam Can the Subaltern Speak menyatakan bahwa perempuan adalah sosok subaltern/bawahan dalam masyarakat yang tidak akan pernah mampu bersuara ataupun medapatkan hak-hak yang selayaknya bagi manusia (Udasmoro, 2018: 185).

Dalam hal ini bahwa perempuan Bali digambarkan sudah terbiasa dengan budaya patriarki yang memosisikan perempuan dalam memandang kerja sebagai persembahan (yadnya) sehingga harus dikerjakan secara tulus ikhlas tanpa memandang adanya ketidakseimbangan antara laki-laki atau perempuan. Perempuan juga diceritakan patuh pada konstruksi bahwa kerja adalah kewajiban sebagaimana swadharma-nya sebagai seorang istri terhadap suami (Ni Nyoman, 2016). 
Pada akhirnya bahwa konstruksi budaya menyebabkan tokoh Kenanga mengorbankan segalanya demi keluarganya dan mengorbankan tubuhnya untuk Bhuana. Hubungan gender yang memiliki keterkaitan erat dengan persoalan-persoalan sosial lainnya, misalnya persoalan etnisitas, kelas sosial, dan sebagainya sebagaimana yang dijelaskan oleh Angela McRobbie,

“...marks the field of'feminism undone'. There is a re-drafing of gender hierarchies, I claim, which has repercussions for questions of social class and race and ethnicity.” (McRobbie, 2009:6)

Dalam karyanya, Oka Rusmini dipahami sebagai penyalur ide kritis atas problematika yang terjadi dalam masyarakat, salah satunya yang berjudul Kenanga. Hal itu dapat dijelaskan bahwa sastra sebagai produk kebudayaan merupakan ilustrasi seluruh kehidupan sosial (Tong, 1998). Berbagai kritik sosial budaya telah dilahirkan melalui karya sastra, yang bukan hanya sekedar silent force melainkan material yang aktif.

Umar Junus (1985: 5-6) menyatakan bahwa novel kelihatannya menghindarkan diri dari kegiatan yang sekadar melaporkan. Novel mungkin hanya menghubungkan dengan satu peristiwa nyata belaka sehingga akan merasa ia benar-benar terjadi. Pernyataan yang tidak kalah penting adalah pernyataan dari Sofia Kartika. Sofia (2003: 130) menyatakan bahwa realita masyarakat, terutama yang berkaitan dengan kehidupan perempuan yang tergambarkan dalam karya sastra, bisa jadi adalah hal-hal yag benar-benar terjadi di dunia nyata. Hal ini disebabkan oleh fungsi yang dimiliki karya sastra sebagai pengolah realita yang ada di masyarakat menjadi sebuah bahan refleksi diri, sehingga sastra sebagai cerminan kehidupan masyarakat merupakan istilah yang tepat untuk menggambarkan realitas tersebut. Penelitian ini berjenis penelitian kualitatif. Data berupa isi teks yang meliputi dialog, kalimat-kalimat, kutipan dalam novel Kenanga (2003) karya Oka Rusmini.

\section{HASIL DAN PEMBAHASAN}

Konstruksi Budaya Pada Tubuh Perempuan Bali dalam Novel Kenanga (2003) karya Oka Rusmini Dalam hal ini perempuan Bali diberikan berbagai batasan yang lebih besar dibandingkan lakilaki. Contohnya saja dalam memilih pasangan hidup, perempuan Bali memiliki keterbatasan dalam menentukan pasangan hidupnya. Seperti pada kutipan yang disampaikan Oka Rusmini dalam novel Kenanga.

"Ibunya selalu mendorongnya untuk rajin menghadiri acara keluarga bangsawan, peluangnya lebih besar untuk mendapatkan jodoh lelaki satu kasta. Itu harapan ibunya. Tatpi bagaimana kalau para lelaki bangsawan itu tidak terpikat dengan perempuan sekasta? Bagaimana kalau mereka justru tertarik pada perempuan sudra? Tentu saja tidak ada masalah! Mereka boleh saja kawin dengan perempuan manapun, bahkan dengan perempuan sudra yang tak jelas asal-usulnya seperti intan. Semetara sebagai perempuan bangsawan, pilihan hanya terbatas pada lelaki yang sederajat. Atau dia akan terkutuk bila melanggar.

Sial rutuh galuh siapa pula yang mengatur kutukan ini! Dan beginilah jadinya sekarang. Agar selamat dari kutukan, supaya hidupnya sejahtera damai sentosa, dia harus memamerkan tubuh dan kecantikannya didepan laki-laki muda dan sederajat. Mereka bilang memilih laki-laki sekasta akan mengharumkan nama keluarga. Tapi, kenapa rasanya seperti menjual diri saja? Apa bedanya 
dengan perempuan-perempuan penjaja tubuh yang beroperasi dipuluhan motel murah di Denpasar" (Rusmini, 2017:152).

Dalam kutipan di atas digambarkan bagaimana sebuah aturan tradisi menempatkan perempuan sebagai individu yang tidak memiliki kekuatan. Terdapat aturan dimana perempuan berkasta Brahmana (kasta tertinggi) tidak diperbolehkan untuk menikah dengan kasta yang lebih rendah darinya. Apabila aturan tersebut dilanggar maka perempuan tersebut akan dibuang dari keluarganya atau bahkan dibuang keluar pulau Bali. Berbeda halnya dengan laki-laki, laki-laki Brahmana dalam aturan kasta Bali diperbolehkan untuk memperistri perempuan dari kasta yang lebih rendah darinya (Sudra). Akan tetapi perempuan Sudra yang dinikahi oleh laki-laki Brahmana tetap tidak dapat memiliki hak yang sama dengan perempuan berdarah Brahmana. Hal tersebut ditunjukan dari tidak diperbolehkannya perempuan Sudra (yang sudah dinikahi Brahmana) untuk ikut sembahyang di merajan-tempat ibadah agama hindu milik keluarga- kaum Brahmana.

Hal ini menunjukan bahwa baik dalam kasta Brahmana maupun Sudra kaum perempuan tetap mengalami subordinasit. Otoritas dan dominasi kaum laki-laki tidak dapat dihilangkan bahkan ketika perempuan berada dalam golongan yang tinggi derajatnya. Perempuan Brahmana dalam kutipan di atas tidak memliki kebebasan dalam menentukan pilihannya, mereka terjebak pada keharusan untuk menikah dengan laki-laki yang memiliki derajat sama dengan dirinya. Dan terdapat pula pada kutipan berikut.

"Tapi ini Bali, Kenanga. Ada adat yang menentukan hidup kita. Apalagi kita bangsawan, dari kasta tertinggi. Tempat kita di Griya. Kita kaum Brahmana dihargai sebagai surya, diagungkan orang. Apa kau tega membiarkan anak kita diperlakukan sebagai sudra, golongan wong jero, abdi rendahan.” (Rusmini, 2017:82-83)

Kutipan di atas menjelaskan antara percakapan Kenanga dengan Bhuana yang membicarakan tentang kehidupan Intan -anak hasil hubungan mereka. Bali begitu kental dengan bersandar pada adat istiadat, terlebih bagi golongan keluarga yang berkasta tinggi, Tidak mudah bagi mereka mendapatkan pasangan, atau pun mengurus anak (yang tiba-tiba saja datang) tanpa ada kejelasan dan berasal dari golongan sudra (rendahan) pula.

Dalam beberapa bagian pada novel Kenanga juga digambarkan sosok ideal perempuan dalam pandangan masyarakat Bali. Perempuan ideal dalam pandangan masyarakat Bali digambarkan sebagai perempuan yang bekerja di rumah. Mereka menyediakan segala keperluan untuk upacara, memuaskan suami, mengurus anak (menjalankan peran motherhood), dan berbagai tugas yang erat kaitannya dengan konsep feminin yang diposisikan di ranah domestik. Perempuan seolah tidak diperbolehkan memiliki ambisi untuk bersaing dengan laki-laki. Konsep feminin seolah menjadi identitas yang harus ada disetiap tubuh perempuan yang dengan hal itu secara otomatis menempatkan perempuan dalam ruang domestik. Pendidikan dan karier dipandang sebagai suatu yang akan menjadi penghambat dalam mencapai gambaran ideal perempuan Bali. Pendidikan dipandang sebagai sesuatu yang akan memperlambat perempuan dalam mendapatkan pendamping dan karir karena dianggap akan menghalangi perempuan dalam 
mengurus rumah tangga. Pandangan-pandangan lama semacam itu yang kemudian membuat perempuan semakin terjebak dalam ruang domestik.

“Anak kita? Bhuana, dimana otakmu? Kau lelaki, bisa bicara apa saja semaumu. Menanggung anak ini, membiayainya. Enak saja. Kau pikir aku tidak sanggup? Persoalannya tidak sesederhana itu. Mungkin bagimu ini soal mudah, buatku berat! Tubuh laki-laki bisa bebas membuang benihnya kemanapun, tapi perempuan? ...” (Rusmini, 2017:49)

Seperti dalam budaya lelaki pada umumnya, kontestasi perempuan disini digambarkan hanya sebagai alat penyalur kebutuhan seks maupun tempat melahirkan. Budaya pada bagian ini meloloskan asumsi 'tubuh laki-laki' menjadi dominasi atas keterpurukan 'tubuh perempuan'. Kenanga dengan lepas mengatakan Bhuana 'bebas...' dalam artian bahwa dirinya telah dikonstruksi dalam budaya sedemikian rupa - baik dalam adat istiadat Bali maupun budaya bias gender - sehingga menyebabkan ketidakpercayaan terhadap lingkaran masyarakat sekitarnya. Seperti dalam kutipan berikut.

“Suatu kali Tuniang berceloteh tentang Dayu Ratna. Mahendra tahu, yang dimaksud adalah seorang perempuan berumur lima puluh tahun, tetapi masih lajang, dan manajer hotel berbintang. Lingkaran pergaulannya memang luar biasa. Meski bagi Mahendra, sebetulnya itu biasa-biasa saja untuk ukuran zaman sekarang. Mungkin masalahnya hanya karena dia dayu, dan tinggal di griya. Tak pelik lagi, jadilah perempuan itu sasaran pergunjingan. Para perempuan griya, termasuk Tuniang, suka sekali memvonisnya yang tidak tidak. (Rusmini, 2017:208-209).

Kutipan ini merupakan kebiasaan yang dilakukan masyarakat Bali dengan menempatkan perempuan sebagai pihak yang dijadikan objek; sebagai sasaran ocehan yang sudah dibiasakan dan dilegalkan oleh budaya. Dalam kalimat 'masalahnya.... dia dayu, dan tinggal di griya'seperti merupakan aturan yang kemudian menciptakan aturan bahwa perempuan seperti kategori di atas - dalam budaya Bali - boleh dijadikan sasaran pergunjingan. Sekilas hal ini tampak biasa saja, namun jika didalami banyak sekali yang melatarbelakangi konflik sosio-kultural semacam ini.

Adapun dalam kutipan berikutnya memperlihatkan bahwa Kenanga begitu menahan rasa cintanya, mengorbankan perasaan dan bahkan pengorbanan tersebut adalah untuk keluarganya sendiri (adiknya) yang harus ia relakan menikah dengan Bhuana, lelaki yang telah menanamkan benih cinta kepada dirinya (Kenanga). Atas asas hukum, negara, bahkan adat seolah mendukung cinta Kencana kepada Bhuana yang kemudian semakin disakralkan dengan ikatan pernikahan.

"Sikap Bhuana yang begitu penuh perhatian seperti ujung runcing keris yang mengorek perasaannya. Memperparah beban sakitnya. Dia adalah laki-laki yang dicintai adiknya sendiri. Cinta itu bahkan telah sah terlindung hokum, adat, dan agama." (Rusmini, 2017: 60)

Karakter Perempuan dalam Novel Kenanga Karya Oka Rusmini

Dalam novel Kenanga -Oka Rusmini tidak hanya menggambarkan perempuan dalam konstruksi budaya Bali. Oka Rusmini juga berusaha memperlihatkan bentuk-bentuk usaha atau perilaku perempuan yang tidak hanya diam dan pasrah terhadap aturan tradisi yang diberlakukan terhadapnya. Oka Rusmini berusaha memperlihatkan dua sisi dari perempuan, -yakni yang berusaha mendobrak aturan yang mengekang kebebasan mereka dan perempuan yang berusaha mencari keselamatan dari hukum alam yang diberlakukan dalam kebudayaan masyarakat Bali 
dengan patuh dan terus menjalankan tradisi. Dua karakter perempuan ini masing-masing digambarkan melalui beberapa tokoh perempuan dalam novel Kenanga.

Karakter perempuan yang berusaha mendobrak tradisi tersebut digambarkan melalui tokoh Kenanga dan Intan, sedangkan tokoh yang terus melanjutkan aturan tradisi atau patuh dengan tradisi dalam hal ini digambarkan melalui tokoh Kencana, Galuh dan beberapa tokoh perempuan lain dalam novel Kenanga. Kenanga sebagai tokoh dengan segala ambisi terutama dalam mendidik putrinya Intan menyimbolkan karakter perempuan tangguh. Berbagai konflik yang dialami Kenanga tidak kemudian membentuknya menjadi perempuan yang menyerah terhadap keadaan. Konflik-konflik yang dihadapi Kenanga justru membentuknya menjadi perempuan yang tangguh dan tidak terpengaruh oleh aturan-aturan tradisi khususnya yang diperuntukan bagi perempuan Bali. Kenanga digambarkan sebagai perempuan yang acuh tak acuh terhadap berbagai aturan masyarakat dan cenderung menunjukan sikap perlawanan terhadap aturan-aturan yang mengekangnya. Contohnya saja dalam mendidik Intan putri angkatnya yang diambil dari kaum Sudra, Kenanga mendidik Intan layaknya seorang Brahmana. Intan dididik sebagai gadis yang memiliki harga diri dan prinsip hidup yang jelas. Ia menghargai diri sebagai seorang perempuan, dan dia sadar bahwa sistem kasta dalam masyarakat mereka tidak bisa merenggut haknya untuk bersaing dan mendapatkan kelayakan layaknya kaum Brahmana. Seperti dalam kutipan berikut.

\footnotetext{
"tapi, susuk ini punya Ratu Ibu. Ibu sendiri yang ajarkan tiang untuk hormat pada Ratu Ibu..." ujar Intan hati-hati

Gadis itu tahu, memakai barang-barang Kenanga adalah tabu. Sebab Kenanga adalah bangsawan, sementara dirinya bukan. Namun Kenagan seakan tidak pernah peduli denga semua tabu itu. Perempuan bangsawan itu tetap saja meminjamkan barang-barang terbaiknya. Ia juga sering membelikan busana kebaya yang sama persis dengan dirinya, baik bahan maupun warna." (Rusmini, 2017:141).
}

Penggalan pernyataan Intan dalam kutipan di atas menunjukan bagaimana sebuah budaya benarbenar mengatur pola tingkah laku masyarakat. Tradisi dan budaya kemudian dibuat sedemikian rupa sebagai sesuatu yang secara otomatis menjadi pengawas guna memastikan segala hal berjalan sesuai pola yang telah dibentuk. Akan tetapi disatu sisi Kenanga yang memiliki status bangsawan nyatanya tidak benar-benar membenarkan setiap aturan yang membedakan status antara kaum Brahmana dan Sudra. Sikap tersebut ditunjukan Kenanga tidak memedulikan penilaian masyarakat yang memandang tabu ketika barang-barang Kenanga sebagai kuam Brahma digunakan oleh Intan yang berasal dari kaum Sudra. Kenanga tidak peduli terhadap pandangan masyarakat bahkan orang tuanya yang menganggapnya aneh. Ia hanya melakukan apa yang disukainya dan yang ia anggap benar.

"Intan tak melihat gurat-gurat usia yang keras menyita wajah perempuan itu. Perempuan yang merawatnya, menyediakan lahan untuk kehidupannya. Dialah yang mengajarinya sopan santun, tata karma yang rumit dalam kehidupan griya. Dia juga melatihnya untuk punya harga diri dan prinsip hidup yang jelas. Tak bosan-bosan ia berpesan: "kau harus berani, Intan. Hidup ini keras. Dan jadi perempuan itu sulit. Tapi, kalau kita tabah dan siap untuk kalah dalam setiap pilihan kita, maka kita bisa menikmati hidup. Kemenangan dan kekalahan bukan hadiah, tetapi bagian dari 
hidup yang harus kita bayar. Itu kewajiban kita kepada hidup. Bukan saja untuk hari ini, tapi juga nanti setelah roh kita lepas dari tubuh". (Rusmini, 2017:140).

Tidak hanya terhadap dirinya, Kenanga juga mendidik Intan menjadi perempuan yang bermartabat layaknya kaum Brahmana, dengan harapan putrinya akan tumbuh sebagai perempuan yang tangguh. Mulai dari tata krama, prinsip hingga tujuan hidup, tidak satupun yang luput dari didikan Kenanga. Kenanga memberikan pendidikan formal terbaik untuk Intan, sehingga Intan tumbuh layaknya perempuan Brahmana walau tanpa menyandang status tersebut. Dalam struktur kasta masyarakat Bali Intan tetaplah seorang gadis yang berkasta Sudra akan tetapi setiap tata krama dan sikap intan mencerminkan kasta Brahmana dengan tetap mengingat posisinya sebagai seorang Sudra. Sikap dan tata krama yang ditunjukan Intan sangat mencerminkan perempuan brahmana akan tetapi rasa hormat dan kepatuhannya sebagai seorang sudra tidak pernah luntur walau Kenanga berusaha menghilangkan hal itu dari putrinya. Kenanga berusaha mendidik Intah selayaknya perempuan Brahmana yang memiliki kebanggaan yang tidak menundukan kepala kepada dan merendahkan diri terhadap orang lain.

Setiap pesan yang disampaikan Kenanga menggambarkan prinsip hidup yang selama ini dipegang oleh gadis tersebut, dimana kemudian ia menjadi perempuan yang teguh dan tidak terkekang oleh aturan budaya. Sosok Kenanga melambangkan ketangguhan yang pada masa itu sangat jarang dimiliki oleh perempuan Bali lainnya. Bagi Kenanga tidak semua aturan budaya baik untuk dipatuhi, perempuan juga memiliki hak untuk mendapatkan kebebasanya bahkan walaupun ia berstatus sebagai Sudra. Hal inilah yang kemudian diturunkan kepada Intan. Seperti pada kutipan berikut.

"Konon begitu banyak gadis yang terpikat pada Mahendra. Intan telah melihat sendiri, betapa gawatnya peran dingin antara Galuh dan Gelung gara-gara memperembutkan lelaki itu. Ia jadi penesaran, betulkanh Mahendra begitu luar biasa? Tiba-tiba Intan merasa tertantang. Sebuah ide mengelebat dalam benaknya. Mungkin dia bisa memikat Mehendra? Menaklukannya, agar para perempuan muda yang cantik-cantik dan bangsawan dan kaya dan sombong itu jadi patah hati semua? Intan tertawa dalam hati. Ini permainan menarik." (Rusmini, 2017:149).

Kutipan di atas menjadi bukti bagaimana Oka Rusmini menghadirkan tokoh Intan sebagai sebuah contoh yang dapat diraih dalam struktur kasta masyarakat Bali. Nilai-nilai kemanusiaan dijadikan Oka Rusmini sebagai penguat dan landasan dari setiap argument dan sudut pandangnya yang sangat menentang sistem kasta dan kostruksi perempuan di masyarakat Bali. Intan menyadari nilai dirinya sebagai sorang perempuan yang memiliki kehormatan walau dengan statusnya sebagai seorang Sudra. Ia memiliki paras yang cantik, perilaku yang baik, bahkan kecerdasan yang mungkin tidak dimiliki perempuan oleh semua perempuan Brahma, ia adalah perempuan yang terdidik. Hal ini yang kemudian disadari Intan sehingga membuatnya merasa pantas untuk mengambil tantangan untuk menarik hati laki-laki Brahmana. Melalui tokoh Intan Oka Rusmini ingin memperlihatkan bahwa aturan kasta dan budaya tidak selamaya dapat mengekang kebebasan perempuan. Perempuan dengan kasta terendah sekalipun bisa memiliki nilai yang lebih tinggi dari kaum Bangsawan. Dalam hal ini Oka Rusmini ingin membuktikan 
bahwa tidak semua perempuan terkekang dalam aturan budaya, perempuan juga memiliki kesempatan untuk mendapatkan kebebasan dalam menentukan pilihannya.

\section{KESIMPULAN}

Perempuan di dalam novel Kenanga ini menjelaskan sosok perempuan Bali yang ambisius, berpegang teguh pada pendiriannya, dan mencoba keluar dari aturan yang mengekangnya. Perempuan dalam tokoh Kenanga, diceritakan mampu mengalahkan sistem yang mendominasi kehidupannya. Kenanga pun digambarkan sebagai sosok yang dapat membuat perempuan lain berdaya dengan menggunakan kasta sebagai cara untuk meningkatkan status sosial perempuan lain, seperti tokoh Intan yang berasal dari kasta Sudra.

Kenanga yang tidak bisa berada di dalam tatanan sosial keluarga untuk tunduk dan patuh atas aturan yang telah diterapkan, ia meyakini dirinya dapat lepas dari aturan-aturan yang mengekang hidupnya sebagai seorang perempuan. Perbedaan yang terjadi pada adiknya, Kencana yang menikah dengan Bhuana. Bhuana seorang lelaki yang telah menanamkan buih cinta terhadap Kenanga, tanpa ada satu pun yang mengetahui akan hal tersebut. Namun Kenanga menyuruh untuk mempertanggungjawabkan hal itu dengan cara menikah dengan Kencana -adiknya.

Seperti yang sudah di bahas diatas bahwa Bali sebagai julukan pulau dewata begitu kental dan saklek terhadap aturan tradisi yang telah melekat pada masyarakat Bali. Namun, dibalik itu semua sebagai perempuan dalam diri Kenanga untuk mengubahnya, melepasnya, bahkan bila bisa dilakukan untuk meniadakannya. Karena dengan perbedaan tersebut membuat sebuah manusia yang disebut "perempuan" dan "laki-laki" tidak sepadan atau tidak setara yang juga berada dalam lingkaran aturan berdasarkan tradisi adat.

\section{DAFTAR PUSTAKA}

\section{Buku}

Butler, Judith. 1988. "Performative Acts and Gender Constitution: An Essay in Phenomenology and Feminist Theory." John Hopkins University Press

McRobbie, Angela. 2009. “The Aftermath of Feminism”. California: SAGE

Putra, I Nyoman Darma. 2003. “Wanita Bali Tempoe Doeloe, Perspektif Masa Kini” Denpasar: Yayasan Bali Jani.

Rusmini, Oka. 2003. “Kenanga”, Jakarta: Grasindo

Tong, Rosemarie Putnam. 1998. "Feminis Thought: Pengantar Paling Komprehensif kepada aliran Utama Pemikiran Kritis.” Yogyakarta: Jalasutra.

Udasmoro, Wening. 2018. "Dari Doing ke Undoing Gender: Teori dan Praktik Kajian Feminisme”. Yogyakarta. Gadjah Mada University Press.

Wiyatmi. 2012. "Kritik Sastra Feminis: Teori dan Aplikasinya dalam Sastra Indonesia." Yogyakarta: Penerbit Ombak. 


\section{Jurnal}

Darmayanti, Ida Ayu Made. 2014. 2 Oktober. "Seksualitas Perempuan Bali Dalam Hegemoni Kasta: Kajian Kritik Sastra Feminis Pada Dua Novel Karangan Oka Rusmini”. Fakultas Bahasa Sastra dan Seni: Universitas Pendidikan Ganesha Singaraja

Rahmawati, Ni Nyoman. 2015. 12 Desember. "Perempuan Bali Dalam Pergulatan Gender (Kajian Budaya, Tradisi, dan Agama Hindu)”. Sekolah Tinggi Agama Hindu Negeri Tampung Penyang: Jurnal Studi Kultural Vol 1

\section{Media dan Media Online}

Asmaudi, Nuryana. 2003. 2 November. “Sajak-sajak Kesaksian Oka Rusmini”. Bali Post, hal. 10

Tanu, I Ketut. 2018. "Bali Aga dala Perubahan Sosial Budaya”. Diakses dari laman: file://C:/Users/acer/Downloads/698-1301-1-SM\%20(1).pdf diakses pada tanggal 24 Mei 2020 pukul 13.00 